\title{
Técnicas de sutura do tubo digestivo em plano único com nós atados no lume, em cães: pontos simples totais versus pontos extramucosos ${ }^{1}$.
}

\author{
One layer sutures of digestive tract knotted in the lumen, in dogs: perforating stitch \\ versus serosubmucosal suture.
}

\author{
João Luiz Moreira Coutinho Azevedo², Cássio Edvan Paulino Da Silva ${ }^{3}$, Otávio Cansanção Azevedo ${ }^{4}$, Manoel De Jesus \\ Simões $^{5}$ \\ 1. Trabalho realizado no Laboratório da Disciplina de Técnica Operatória da Universidade Federal de São Paulo \\ 2. Professor de Cirurgia da Universidade Federal de São Paulo (UNIFESP) \\ 3. Monitor de Técnica Operatória e Cirurgia Experimental da UNIFESP \\ 4. Mestrando do Programa de Pós-Graduação em Cirurgia e Experimentação da UNIFESP. Monitor de Técnica Operatória \\ e Cirurgia Experimental da UNIFESP. Médico-Asisstente de Gastroenterologia Cirúrgica do Hospital do Servidor Público \\ do Estado de São Paulo \\ 5. Professor Titular e Chefe de Disciplina de Histologia da UNIFESP
}

\section{RESUMO}

Objetivo: Comparar a anastomose do tubo digestivo em plano único com nós atados no lume por sutura com pontos totais versus pontos extramucosos. Métodos: Foram operados seis cães, com realização de duas secções transversas do jejuno a $30 \mathrm{~cm}$ e a $70 \mathrm{~cm}$ da flexura duodenojejunal e sutura, na face posterior com pontos extramucosos atados sobre a submucosa, e na face anterior com pontos totais atados sobre a mucosa. No $7^{\circ} \mathrm{PO}$ foram avaliadas, na face posterior, as aderências na linha de sutura e feitos exames macroscópico e microscópico. Resultados. As aderências peritoneais foram mais profusas nas suturas extramucosas com tecido aderencial sobre a linha de sutura, sem reconstituição da serosa, ou com a deformidade cicatricial das serosas dos cotos angulando a anastomose. A serosa teve boa reconstituição nas suturas totais. O epitélio mucoso reconstituiu-se perfeitamente nas extramucosas, mas não nas totais. Nas suturas totais houve focos residuais de inflamação aguda.O realinhamento, a reestruturação e a regeneração das camadas (exceto a serosa, cuja regeneração foi prejudicada por aderências) foi melhor na sutura extramucosa que na total. A muscular da mucosa não se regenerou em nenhuma anastomose. Os polimorfonucleares, os macrófagos, os fibroblastos e as fibras colágenas foram mais numerosos (significância estatística) na sutura total. Conclusão: As suturas totais da parede posterior da anastomose com nós atados no lume, sobre a mucosa, são seguras, apesar da inflamação maior. A sutura extramucosa da parede posterior, com nós atados no lume, sobre a submucosa, propicia a formação de aderências peritoneais, devendo ser evitada.

Descritores: Anastomose cirúrgica. Intestino delgado. Modelos animais. Cães.

\begin{abstract}
Objective: To compare hand sewn digestive tract single layer anastomosis with knots tied in the lumen: total stitches versus serosubmucosal. Methods: Six mongrel dogs were submitted to laparotomy, each one with two transversal jejunum sections, 30 and $70 \mathrm{~cm}$ far from Treizt angle and suture, serosubmucosal and total stitches, both with knots tied in the lumen, over the mucosa, at the posterior wall. After slaughter (7th post-operative day) was evaluated the peritoneal adhesions at posterior wall. The macro and microscopic features was observed. Wilcox on rank sum test was applied for the histhometry. Results. More profuse adhesions with the serosubmucosal stitches tied in the lumen with adherence tissue over the suture line, avoiding the serosa, within or without healing deformation of the suture lines, doing an anastomosis'angle. There was good serosa reconstitution with total stitches. The epithelium was perfectly reconstituted at serosubmucosa, but not at total stitches, where was residual focus of acute inflammation. The reline and regeneration of wall components (except the serosa, whose regeneration was impaired by peritoneal adherences) were better with serosubmucosal then total stitches. The muscularis never regeneration in anyone suture. The polimorphonuclear cells, macrophages, fibroblasts, and collagen fibers was more numerous (statistical significance) at total stitches. Conclusion: Total stitches with knots tied in the lumen, at posterior wall, over the mucosa are safe full, despite of major inflammation. Serosubmucosal with knots tied in the lumen, at posterior wall, over the mucosa, allows peritoneal adherences formation, and should be avoided.
\end{abstract}

Key words: Anastomosis, Surgical. Intestine, small. Models, animal. Dogs. 


\section{Introdução}

A sutura extramucosa em plano único do tubo digestivo foi inicialmente preconizada com a técnica asséptica (cotos fechados), a pontos separados de colchoeiro (em U), atados na superfície serosa ${ }^{1}$. Com a popularização dos métodos abertos, foram recomendados pontos simples extramucosos atados no lume do órgão, sobre a submucosa, em toda a anastomose ${ }^{2-6}$, ou apenas na face posterior, com a anterior suturada com pontos atados na serosa ${ }^{7-11}$, ou toda a anastomose suturada com pontos extramucosos atados na serosa ${ }^{12-15}$. Por outro lado, foi recomendada a sutura em plano único total, com pontos atados na serosa, na face anterior, e atados na mucosa, na face posterior ${ }^{16-27}$, ou pontos atados na serosa em toda a extenso da sutura ${ }^{14,15,28-30}$. A anastomose extramucosa com pontos atados no lume na face posterior, sobre a submucosa, e pontos atados na serosa, na face anterior, a mais popular ${ }^{7-11}$. Entretanto, para contornar dificuldades na colocação dos pontos na face posterior das anastomoses retocólicas (Chez les sujets obèse ... il-y-a quasi impossible ... charger cette précieuse sous- muqueuse ${ }^{30}$ ), foram colocados de pontos totais atados no lume, sobre a mucosa, com resultados clínicos tão bons quanto com os pontos extramucosos atados no lume, sobre a camada submucosa ${ }^{31}$. O objetivo deste trabalho é estudar comparativamente a cicatrização da face posterior de anastomose do intestino suturado em plano único com pontos extramucosos atados no lume, sobre a submucosa, versus com pontos totais atados no lume sobre a mucosa.

\section{Métodos}

Foram operados seis cães machos, sem raça definida, saudáveis, pesando entre 7 e $12 \mathrm{~kg}$, procedentes do Canil da Escola Paulista de Medicina. Os animais foram anestesiados com pentobarbital sódico a $30 \mathrm{mg} / \mathrm{kg}$. Foram realizadas duas secções transversas do jejuno, uma a $30 \mathrm{~cm}$ e outra a $70 \mathrm{~cm}$ da flexura duodenojejunal, seguida da realização da sutura em estudo na face posterior de anastomose extramucosa (pontos extramucosos atados no lume, sobre a submucosa - figura 1) ou de anastomose total (pontos totais especiais de Gambee atados no exterior, sobre a serosa - figura 2). Em ambas as suturas foram utilizados pontos simples separados de polipropileno monofilamentar azul 4-0, pré-montado em agulha de 2 cm (3/8 de círculo), intervalados de $3 \mathrm{~mm}$. Em três animais a sutura total era proximal e a extramucosa era distal; nos outros três a situação era inversa. No $7^{\circ}$ dia pós-operatório os cães foram sacrificados e necropsiados, com vistas especiais para peritonite, deiscências, fístulas e abscessos perianastomóticos. As aderências na linha de sutura foram avaliadas mediante um escore, no qual foi atribuído um ponto por cada quarta parte da extensão da linha de sutura comprometida com aderências. Na microscopia (H-E e Masson) foram contados neutrófilos, macrófagos, fibroblastos e fibras colágenas. Foi utilizada a prova de Wilcoxon para duas amostras relacionadas $(p=0,05)$.

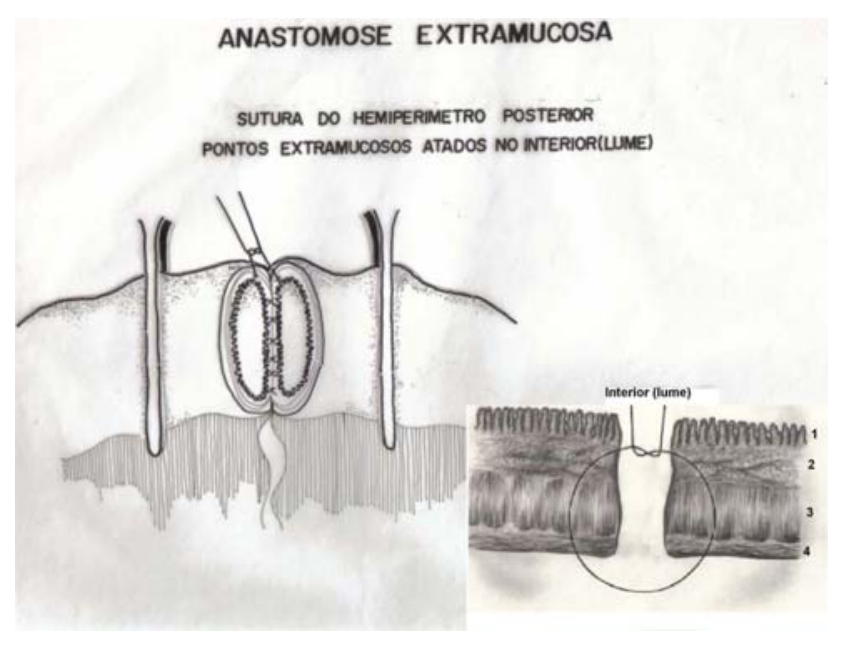

FIGURA1 - Sutura extramucosa (parede posterior). A agulha penetra na espessura da parede do coto intestinal entre as camadas mucosa e submucosa, progredindo em direção ao exterior da víscera, dessa forma transfixando a submucosa (2), a muscular (3) e a serosa (4), de dentro para fora do lume intestinal; a seguir a agulha penetra na parede do coto intestinal oposto a partir da serosa, transfixando a muscular e a submucosa e emergindo no interior do intestino, entre a mucosa e a submucosa. O nó é atado no lume do órgão, sobre a camada submucosa, ao nível do interstício dos dois cotos que estão sendo suturados. A membrana mucosa (1) permanece intocada.

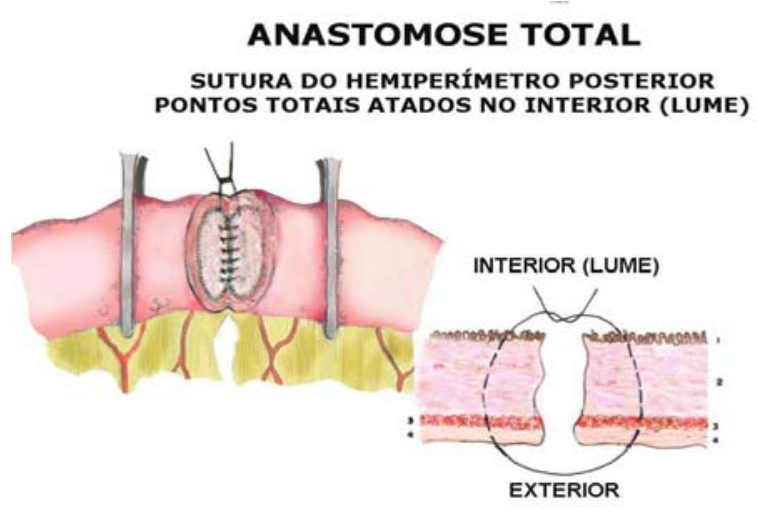

FIGURA 2 - Sutura total (parede posterior). Inicia-se a execução do ponto de dentro para fora de um dos cotos intestinais, mediante a perfuração das camadas mucosa (1), submucosa (2), muscular (3) e serosa (4), até o exterior do intestino. A seguir, a agulha executa um movimento de fora para dentro do coto intestinal oposto, transfixando todas as camadas e emergindo no lume do órgão. Os nós são atados na superfície da camada mucosa. 


\section{Resultados}

Não houve complicações clinicamente evidenciadas no pós-operatório. Na necrópsia observou-se que não havia peritonites, abscessos perianastomóticos, deiscências ou fístulas. As aderências peritoneais foram mais profusas nas extramucosas (tabela 1). Ao exame macroscópico constatouse que nas anastomoses extramucosas havia tecido perianastomótico sobre a linha de sutura, e a serosa não estava reconstituída (figura 3 ). A serosa teve boa reconstituição nas suturas totais (figura 4). A mucosa se apresentou perfeitamente reconstituída nas suturas extramucosas (figura 5), mas não nas totais (figura 6). No exame histopatológico das suturas totais foi constatado permanência de focos de inflamação aguda (figura 7). O realinhamento, a reestruturação e a regeneração das camadas (exceto a serosa) foi melhor na sutura extramucosa que na total. A muscular da mucosa não se regenerou em nenhuma anastomose. A morfometria demonstrou que os polimorfonucleares, os macrófagos, os fibroblastos e as fibras colágenas foram mais numerosos (significância estatística) na sutura total (tabela 2 e figura 7).

TABELA 1 - Escore das aderências peritoneais. Pela prova de Wilcoxon: EP > TP*

* significância estatística.

\begin{tabular}{cc}
\hline $\begin{array}{c}\text { Sutura extramucosa } \\
\text { posterior (EP) }\end{array}$ & Sutura total posterior (TP) \\
\hline 4 & 0 \\
4 & 1 \\
2 & 0 \\
4 & 0 \\
3 & 2 \\
3 & 0 \\
$\mu=3,3$ & $\mu=0,5$ \\
\hline
\end{tabular}

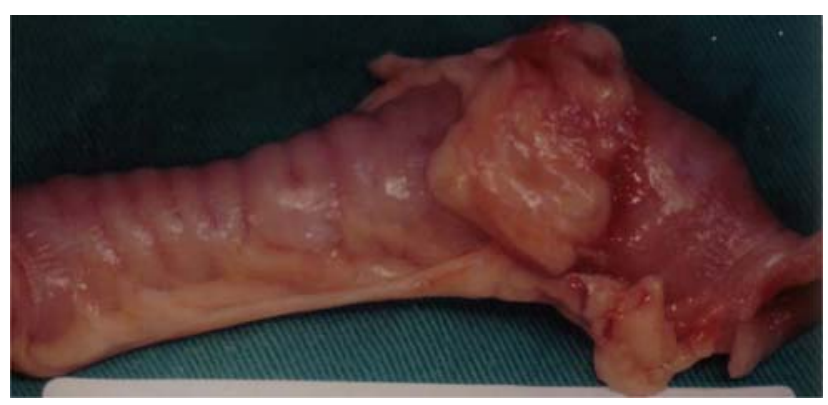

Figura 3 - Fotografia de peça de necrópsia ( $7^{\circ}$ dia P.O.) evidenciando a face posterior de segmento jejunal fechado, contendo sutura extramucosa com nós atados no lume, com grande omento aderido em 3/4 da extensão da linha de sutura da face posterior, impedindo a reconstituição da serosa (escore de aderências $=3$ ).

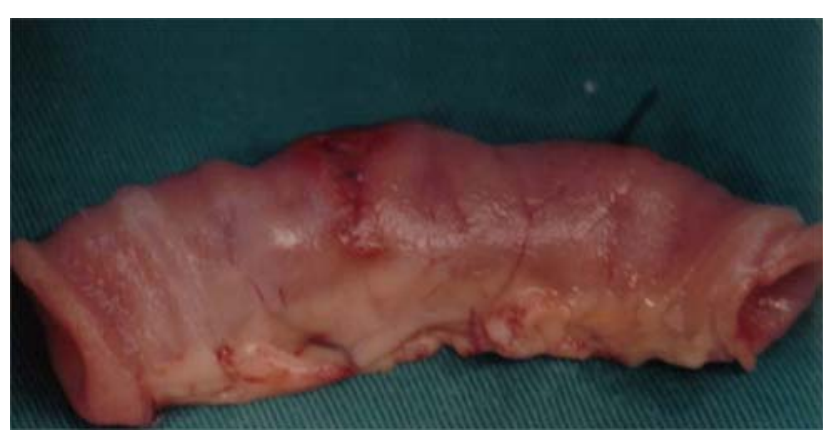

FIGURA 4 - Fotografia de peça de necrópsia evidenciando a face posterior de segmento jejunal fechado, contendo sutura total com nós atados no lume, com perfeita reconstituição da serosa (escore de aderências $=0$ ).

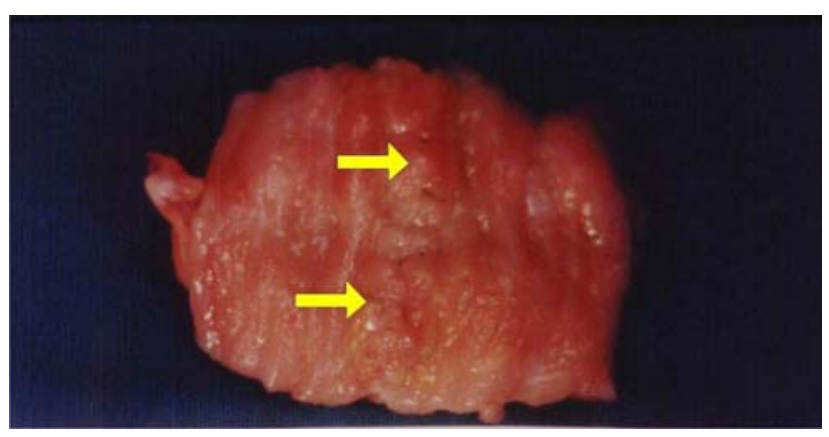

FIGURA 5 - Fotografia (peça de necrópsia) da superfície mucosa de segmento jejunal no $7^{\circ}$ dia após sutura extramucosa com nós no lume, aberto por secção longitudinal de sua borda antimesentérica, evidenciando aspecto de completa regeneração do epitélio mucoso, com a linha de sutura quase imperceptível (setas).

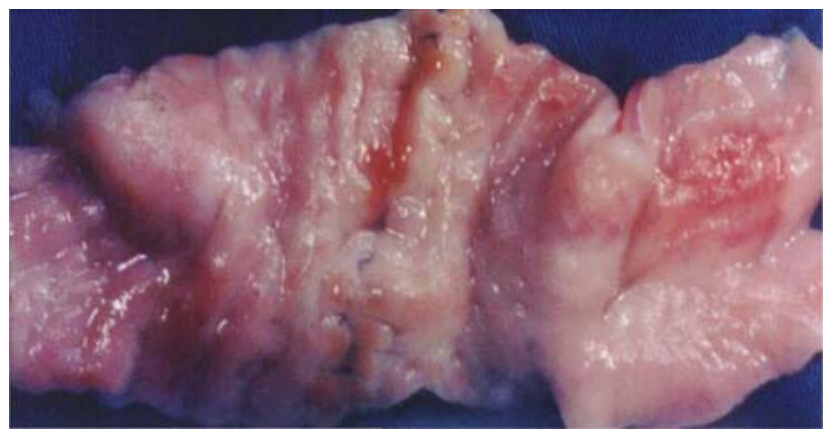

FIGURA 6 - Fotografia (peça de necrópsia) da superfície mucosa de segmento jejunal no $7^{\circ}$ dia após sutura total com nós no lume, aberto por secção longitudinal de sua borda antimesentérica, evidenciando aspecto de inflamação aguda residual (hiperemia) na linha de sutura (setas). 


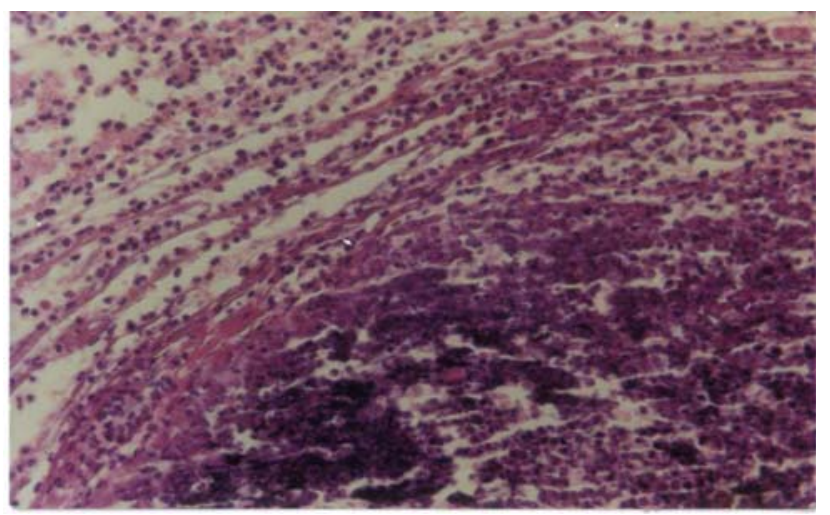

FIGURA 7 - Fotomicrografia (100 x) em zona de anastomose de parede jejunal suturada com pontos totais. Observa-se abundante infiltrado celular inflamatório e áreas de edema.

\section{Discussão}

Há o pressuposto de que a transfixação do intestino por fios de sutura propicia contaminação peritoneal continuada mediante bactérias veiculadas por escapes do conteúdo intestinal. Entretanto, Jourdan (1965) ${ }^{32}$, reavaliando suas conclusões pioneiras quando preconizou a sutura extramucosa, tornou-se partidário do ponto perfurante total nas anastomoses em plano único, ao invés do extramucoso. Esse autor ${ }^{32}$ acreditava na capacidade da submucosa, mercê de sua grande elasticidade, de funcionar à maneira de um esfíncter sobre o fio que a atravessa, impedindo escapes. Dessa forma, nega a possibilidade de contaminação peritoneal às expensas de escapes do conteúdo visceral através da perfuração pelo fio de sutura, na anastomose em plano único total. Entretanto, quando o mecanismo de proteção representado pela camada mucosa aderida internamente à linha de sutura é perturbado, escapes ocorrem através da anastomose, conforme foi demonstrado em anastomoses com evaginação da mucosa ${ }^{33}$, mediante a recuperação em culturas de tecidos perianastomóticos positivas para uma bactéria não residente do intestino de cães (S. marcescens), introduzida no lume intestinal proximal à anastomose após esta estar completada. Entretanto, é sabido que o englobamento da mucosa nas anastomoses em plano único total condiciona a necrose avascular dessa camada ao nível da linha de sutura - o que não ocorre em relação sutura extramucosa, a qual preserva a vascularização da mucosa ${ }^{22}$ - com conseqüentes distúrbios da cicatrização e regeneração das camadas intestinais ${ }^{14,15}$. Nesta pesquisa esses aspectos foram confirmados, com a observação de distúrbios da cicatrização (hipermia e esfacelo da mucosa; zonas de necrose avascular; microabscessos; reação tipo corpo estranho ativo ou imunogênico ao fio de polipropileno) nas suturas totais com nós atados no lume, sobre a mucosa. Por outro lado, foi constatado ${ }^{34}$ que, na anastomose extramucosa em plano único de sutura, a borda mucosa não sofre necrose nem esfacelo, e conserva seu poder de absorção. As suturas extramucosas com nós atados no lume, desta pesquisa, tiveram cicatrização e regeneração de parede mais regular (exceto a serosa).
TABELA 2 - Histometria de macrófagos, fibroblastos, fibras colágenas e neutrófilos por campo microscópico (média de 5 campos). Pela prova de Wilcoxon: EP $<$ TP* para todos os elementos analisados (* significância estatística), onde EP representa a sutura extramucosa posterior e TP a sutura total posterior.

\begin{tabular}{cccccccc}
\hline \multicolumn{2}{c}{ Macrófago } & \multicolumn{2}{c}{ Fibroblastos } & \multicolumn{2}{c}{ Fibras Colágenas } & \multicolumn{2}{c}{ Neutrófilos } \\
\hline EP & TP & EP & TP & EP & TP & EP & TP \\
3 & 8 & 3 & 11 & 17 & 39 & 2 & 14 \\
2 & 7 & 2 & 9 & 17 & 47 & 1 & 12 \\
2 & 8 & 3 & 10 & 21 & 41 & 2 & 11 \\
1 & 3 & 4 & 9 & 23 & 29 & 1 & 8 \\
3 & 6 & 2 & 15 & 25 & 39 & 2 & 13 \\
2 & 5 & 2 & 9 & 23 & 44 & 2 & 13 \\
\hline 13 & 37 & 16 & 63 & 126 & 237 & 10 & 71 \\
\hline
\end{tabular}

Entretanto, as aderências peritoneais foram muito mais profusas que nas suturas totais. Isso se deveu, provavelmente, a escapes de conteúdo intestinal ocorrido entre os pontos, por ter sido "elevada” a camada mucosa pelos nós, os quais, para serem eficazes em fios de polipropileno, devem ser confeccionados com nó de cirurgião inicial e três nós simples sobrepostos, dada à capacidade deslizante desse fio $^{6}$. A camada mucosa, "elevada" (afastada) da linha de sutura mediante a presença de nós volumosos de polipropileno atados na submucosa, no lume do órgão, determina a perda da função de impermeabilização que a mesma exerce na sutura. Essa perda de impermeabilização da linha de sutura determina escapes do conteúdo intestinal para a cavidade peritoneal, com semeadura de bactérias na serosa e tecidos perianastomóticos. A reação orgânica a essa situação é o combate à contaminação mediante o incremento da formação de aderências peritoneais perianastomóticas. De fato, nesta pesquisa, as aderências foram significantemente mais profusas na sutura extramucosa com nós no lume. Por outro lado, o envolvimento da mucosa na sutura cursa com aumento significante de células inflamatórias e de fibras colágenas intramurais, principalmente por causa da necrose avascular que essa técnica determina sobre a camada mucosa envolvida na linha de sutura.

\section{Conclusões}

1. As suturas totais da parede posterior da anastomose com nós atados no lume, sobre a mucosa, são seguras, apesar da inflamação maior.

2. A sutura extramucosa da parede posterior, com nós atados no lume, sobre a submucosa, propicia a formação de aderências peritoneais, devendo ser evitada.

\section{Referências}

1. Halsted WS. Circular suture of the intestine: an experimental study. Am J Med Sci. 1887;94:436-61.

2. Delannoy E, Lagache G, Soots G. A propos des 
anastomoses digestives en un plan. Mm Acad Chir. 1957;83:405-6.

3. Gorodiche J, Jourdan P. Anastomoses digestives en un plan de suture. Sem Hp (Paris). 1951;27:3740-7.

4. Thomeret G, Dubost C, Validire J. Emploi systmatique des anastomoses en un plan sero-musculaire en chirurgie digestive. Mm Acad Chir. 1957;83:407-13.

5. Seylan H, Erel S, Couinaud, Vauclin, Monod-Broca. Statistiques de sutures digestives en un plan. Mm Acad Chir. 1957;83:399-404.

6. Senyk J, Rank F. Oesophageal tissue reaction to different suture materials: an experimental study in the cat. Scand J Thorac Cardiovasc Surg. 1978;12:265-73.

7. Faria, P.A.J. Sutura gastro-intestinal em plano único extramucoso e em 2 planos, um total e um seromuscular invaginante. São Paulo. 1972,106p. (Tese - Doutoramento - Escola Paulista de Medicina).

8. Leonardi LS. Resultados do emprego da sutura em plano único extramucoso na cirurgia gástrica. Campinas. 1973. (Tese - Livre Docência - Faculdade de Ciências Médicas da Universidade Estadual de Campinas).

9. Mantovani M. Sutura seromuscular extramucosa em plano único na cirurgia do intestino. Campinas. 1973. (Tese Doutorado - Faculdade de Ciências Médicas da Universidade Estadual de Campinas).

10. Nigro AJT. Anastomoses esôfago-esofágicas cervicais término-terminais em dois planos de sutura, em plano único extramucoso e por invaginação: estudo comparativo experimental em coelhos. São Paulo. 1990. (Tese - Livre Docência - Escola Paulista de Medicina).

11. Warde JP. Anastomose colorretal experimental em um e dois planos de sutura. Estudo comparativo. São Paulo 1972,122p. (Tese - Doutoramento - Faculdade de Medicina da Universidade de São Paulo).

12. Mantovani M, Leonardi LS, Alcantara FG, Medeiros RR. Estudo comparativo entre diferentes variedades de sutura em um e dois planos no intestino delgado. Trabalho experimental em coelhos. Rev Ass Med Bras. 1976;22:79-86.

13. Kerscher P, Wnsch PH, Steidl H. Naht der Submucosa bei der Dickdarmanastomose. Chirurg. 1979;50:770-4.

14. Azevedo JLMC. Estudo comparativo entre as anastomoses em plano único extramucoso e total, em colo de coelhos. São Paulo. 1988,108p. (Tese - Mestrado - Escola Paulista de Medicina).

15. Azevedo JLMC, Goldenberg S, Simes MJ, Stavale JN. Estudo comparativo entre as anastomoses em plano único extramucoso e total, em colo de coelhos. Acta Cir Bras. 1990;5:6-12.

16. Azevedo JLMC. Estudo comparativo de métodos de suturas intestinais: intestino delgado de cães. In: Congresso Brasileiro De Medicina Militar, 5, Rio de Janeiro, 1972. Temas Livres.

17. Azevedo JLMC. Estudo comparativo de métodos de suturas intestinais: intestino grosso de coelhos. In: Congresso Brasileiro De Medicina Militar, 5, Rio de
Janeiro, 1972. Temas Livres.

18. Azevedo JLMC. Experiência clinica com a sutura de Gambee. In: congresso brasileiro de medicina militar, 5, Rio de Janeiro, 1972. Temas Livres.

19. Azevedo JLMC, Simes MJ, Stavale JN, Novo NF, Juliano Y. Avaliação da cicatrização e da integridade do colo anastomosado após rotação, em coelhos. Ver Col Bras Cir. 1992;19:120-5.

20. Azevedo JLMC, Simes MJ, Santos P, Novo NF. Anastomoses em plano único extramucoso versus anastomoses em plano único total, em jejuno de cães. In: Congresso Brasileiro De Cirurgia, 20, Rio de Janeiro, 25 a 29 de julho de 1993.

21. Azevedo JLMC, Fujimura I, Boarini P, Scomparini CE. Análise da evolução pós-operatória de pacientes submetidos a anastomoses do tubo digestivo em plano único de sutura. In: Congresso Brasileiro De Cirurgia, 20, Rio de Janeiro, 25 a 29 de julho de 1993.

22. Barreto H, Medeiros AC, Garcia OS, Miranda LCD. Vascularização das paredes intestinais subseqüentes aos diversos tipos de sutura. Estudo experimental em cães. Rev Col Bras Cir. 1983;10:203-7.

23. Everett WG. A comparison of one layer and two layer techniques for colorectal anastomosis. Br J Surg. 1975;62:135-40.

24. Gambee LP. A single layer open intestinal anastomosis applicable to the small as well as the large intestine. West J Surg 1951;59:1-5.

25. Gambee LP, Garnjobst W, Hardwick CE. Ten years experience with a single layer anastomosis in colon surgery. Am J Surg. 1956;92:222-7.

26. Hamilton JE. Reappraisal of open intestinal anastomoses. Ann Surg. 1967;165:917-24.

27. Mcadams AJ, Meikle AG, Taylor JO. One layer or two layer intestinal anastomoses? Am J Surg. 1970;120:546-50.

28. Abramowitz HB, McAlister WH. A comparative study of small-bowel anastomoses by angiography and microangiography. Surgery. 1969;66:564-9.

29. Abramowitz HB, Butcher HR. Everting and inverting anastomoses: an experimental study of comparative safety. Am J Surg. 1971;121:52-6.

30. Weinberg JA. Vagotomy and piloroplasty in the treatment of duodenal ulcer. Am J Surg. 1963;105:347-51.

31. Soupault R. Note sur la place et les limites de la suture points perforants en chirurgie digestive. Mm Acad Chir. 1961;87: 530-4.

32. Jourdan P. Sutures en un plan des tuniques digestives: position actuelle. J Chir. 1965;90:649-55.

33. Rusca JA, Bornside GH, Cohn Jr I. Everting versus inverting gastrointestinal anastomoses: bacterial leakage and anastomotic disruption. Ann Surg. 1969;169:727-35.

34. Sabin FR. Healing of end-to-end intestinal anastomoses with especial reference to the regeneration of bloodvessels. Johns Hopkins Hosp Bull. 1920;31:289-99. 
Correspondência:

Prof. João Luiz M. C. Azevedo

Rua Botucatu 740

Prédio da Técnica Operatória

Cep 04023-900

V. Clementino

São Paulo - SP

Jozevedo.dcir@epm.br

www.cirurgiaonline.med.br
Conflito de interesse: nenhum Fonte de financiamento: nenhuma

Recebimento: 10/11/2004

Revisão: $14 / 12 / 2004$

Aprovação: 18/04/2005

\section{Como citar este artigo:}

Azevedo JLMC, Silva CEP, Azevedo OC, Simões MJ. Técnicas de sutura do tubo digestivo em plano único com nós atados no lume, em cães: pontos simples totais versus pontos extramucosos. Acta Cir Bras [serial online] 2005 Mar-Abr; 20(2). Disponível em URL: http://www.scielo.br/acb

Figuras coloridas disponíveis em http://www.scielo.br/acb 